\title{
El Proceso de Aislamiento Económico de Chile de la Región
}

\author{
HUGO FAZIO
}

MAGALY PARADA

El alejamiento de Chile de los países de la región no es un hecho que aparezca súbitamente, sino que constituye un proceso en curso y que es consecuencia del modelo económico elegido, expresándose tanto en los años de dictadura como durante los gobiernos de la Concertación y que se extiende desde que Pinochet decidió retirarse del Pacto Andino hasta la firma del TLC con EE.UU.. Por tanto, no se trata de una casualidad. Como en muchos aspectos, los gobiernos de la Concertación fueron continuadores de la política escogida durante los años de dictadura.

El retiro de Chile del Pacto Andino, bloque de integración constituido a partir de la firma del Acuerdo de Cartagena en 1969, se fundamentó en la existencia de criterios arancelarios diferentes y en regulaciones que dicho acuerdo imponía a la inversión extranjera. Estas disposiciones estaban en contradicción con el nuevo modelo económico en aplicación. Al retirarse Chile del Pacto Andino en 1976, se le propinó un golpe a las industrias que se crearon o desarrollaron teniendo presente el mercado ampliado. El Pacto Andino tiene actualmente un mercado de cien millones de personas. Sus países miembros, Perú, Colombia, Ecuador, Bolivia y Venezuela, han intensificado considerablemente su intercambio comercial, aunque no han logrado constituir una zona de libre comercio.

En este proceso un segundo hito decisivo que aparece es la decisión de los gobiernos de la Concertación, de no integrarse como miembro al Mercosur, decisión que en la práctica se concretó finalmente, optando por la alternativa de negociaciones bilaterales con EE.UU. hasta conseguir la suscripción del TLC durante el año 2003.

\section{La Decisión de no Incorporarse al Mercosur.}

Los gobiernos de la Concertación pusieron siempre en primer lugar llegar a acuerdo con EE.UU. desde que se lanzó a comienzos de los noventa la llamada Iniciativa 
para las Américas que proponía ir creando un mercado libre en el hemisferio occidental a través de una sucesión de acuerdos bilaterales. EE.UU. eligió este camino por ser el más favorable a sus intereses. De esta manera, impedía que los países de la región le presentasen demandas colectivas. La política del Gobierno Aylwin resultó funcional a este propósito. Al hacerlo así, dejó de lado la posibilidad de apoyar acuerdos de integración latinoamericanos, los cuales aparecían claramente como un paso previo necesario, desde el ángulo de los intereses de los países de la región, para negociar con EE.UU. o con acuerdos de integración como la Unión Europea.

Esta conducta de no generar acuerdos de integración regionales no se concilió con declaraciones públicas efectuadas por el propio Presidente Aylwin. En entrevista concedida al diario mexicano Excelsior, Aylwin señaló, a mediados de 1991, analizando precisamente la asociación de EE.UU. con países de la región, una gran verdad. «La diferencia de poder es tan grande -dijo- que la igualdad resulta más bien simbólica. Una igualdad real -señaló- sólo podemos conquistarla en la medida que nosotros estemos unidos. Para mi es una pena que los latinoamericanos llevemos casi dos siglos hablando del sueño de Bolívar y hayamos avanzado tan pocon (Excelsior 04/07/91).

En los hechos, el gobierno chileno decidió la no inserción en un acuerdo regional. Así se demostró al constituirse el Mercosur, formado por Brasil, Argentina, Paraguay y Uruguay. El Gobierno Aylwin, pese a haber sido invitado a integrarse en 1990 -cuando Brasil y Argentina decidieron ampliar el proceso de integración que estaban viviendo desde la década de los ochenta- prefirió restarse a la iniciativa. Los países integrantes del Mercosur conscientes de la importancia de la incorporación chilena dejaron abierta la posibilidad de que ello pudiese darse en cualquier instante, al establecer en el texto de su acuerdo la disposición a acoger de inmediato la adhesión de un país miembro de la ALADI, que no pertenezca a ningún otro esquema de integración. Chile es el único país que se encontraba en esta situación. Los restantes países miembros de la ALADI pueden también adherirse, pero su incorporación entraría en vigencia recién cinco años después de la entrada en funcionamiento del Tratado. El Gobierno Aylwin nunca se planteó la alternativa de aprovechar la posibilidad existente.

La decisión oficial, provocó posiciones encontradas al interior de las fuerzas identificadas con la Concertación. El diario "La Epoca»-muy cercano a la Democracia Cristiana- calificó la actitud gubernamental de "posición ambigua, cuyos motivos resultan difíciles de comprender, ya que la dilación en este terreno, no parece proporcionar beneficio alguno ni al país ni al Gobierno" (04/04/91). Los hechos posteriores le dieron la razón.

La determinación de marginarse del Mercosur fue, en un alto grado, producto de la política de privilegiar la «Iniciativa Para las Américas» del presidente Bush. La 
estrategia estadounidense puso en primer plano un acuerdo separado con Chile. De allí que, altos personeros estadounidenses se felicitasen públicamente de la determinación del Gobierno Aylwin de restarse al Mercosur. «El Gobierno chileno -declaró, a manera de ejemplo, el ex subsecretario de Estado para Asuntos Latinoamericanos de la Administración Reagan, Elliot Abrahams- adoptó una actitud correcta al marginarse de ese acuerdo e intentar empezar por un tratado con EE.UU. y no con sus vecinos, Brasil o Argentina, cuya situación económica no es la misma. Sería un error -añadió- que EE.UU. esperara la formación de ese grupo en el cono sur para negociar con Chile» (31/03/95).

El no integrarse al Mercosur se argumentó oficialmente -tal como lo hizo Elliot Abrahams- en base a las distintas situaciones económicas de unos y otros países. El Ministro de Hacienda de Aylwin, Alejandro Foxley lo fundamentó en las diferencias en materia de políticas macroeconómicas, particularmente con Brasil, y en que se pudiesen trasladar a la economía chilena fenómenos de inestabilidad existentes en los países del Mercosur, además de las distancias en los niveles arancelarios. En definitiva, en estas argumentaciones estaba presente la idea, muy divulgada en los años de dictadura y posteriormente, de que Chile se encontraría en otra etapa en su evolución económica y, por lo tanto, en esta fase los objetivos del país no serían coincidentes con los que tienen los restantes países de la región.

El diario "La Epoca», editorializó con razón, además, que el Mercosur «renueva la importancia de un frente común latinoamericano para equilibrar los números a la hora de negociar con nuestros mucho más poderosos vecinos del norte». De otra parte, la relativa mejor situación chilena, lejos de justificar la no incorporación, la hacía aún más importante, dado que ello permitiría desempeñar un papel más relevante al interior del mercado integrado, con ventajas para el país y cada una de las naciones participantes.

Históricamente, las experiencias de integración latinoamericanas no han dado los resultados esperados. Despertaron grandes esperanzas, que se desvanecieron muy pronto. Así aconteció, por ejemplo, con la Asociación Latinoamericana de Libre Comercio (ALALC), creada en el Tratado de Montevideo de 1960. En la década de los noventa, obtener éxitos en este terreno constituía un desafío fundamental, dada la fuerza que adquirió la constitución de megamercados a nivel mundial.

\section{Mercosur: Potencialidades y Puntos Oscuros.}

Al iniciarse el gobierno Lagos renació la posibilidad de que Chile se incorporase al Mercosur. El presidente Lagos en sus visitas de Estado durante el año 2000 a Argentina y Brasil manifestó que Chile privilegia, en el plano de las negociaciones internacionales, la incorporación al Mercosur, en base a coordinar políticas 
macroecomómicas y a producir un acercamiento de los niveles arancelarios, aceptando -recalcó- la especificidad chilena de contar con aranceles más bajos, estableciéndose un cronograma de aproximación (03/06/00). Anunció que se estudiaba la posibilidad de solicitar oficialmente antes de finalizar el 2000 la incorporación del país al tratado regional.

Obviamente, constituía un gran progreso si la inserción en los procesos de integración se efectuaban colocando al Mercosur como referente central y buscando desde allí otros entendimientos. Desde luego, la incorporación debía efectuarse teniéndose presente las contradicciones al interior del bloque regional, las complejidades del proceso que enfrentaba, el predominio en su interior de políticas económicas regresivas, y buscando enfrentar el agravamiento de los problemas sociales que predominan en la zona.

En el terreno arancelario, finalmente, se abrió camino la idea de que la convergencia entre Chile y el Mercosur se produjese en base a la reducción progresiva del Arancel Externo Común, de 14\% promedio, existente en el tratado de integración del cono sur. El presidente de Brasil, Fernando Cardoso lo explicitó en vísperas del viaje a su país efectuado en julio de 2000 por Ricardo Lagos. «No sería yo -manifestó Cardosoquien pidiera que Chile aumentara sus tarifas externas para que ellos puedan entrar el Mercosur. Seré yo quien pida a nuestros compañeros de los otros países que entiendan que las tarifas tendrán que bajar para que encontremos un camino de equilibrio» (13/ 07/00). Se abandonó así la exigencia de que para llegar al acuerdo Chile aumentase los aranceles, lo cual entraba en contradicción con la política seguida. Las posibilidades reales de incorporación de Chile al Mercosur se despejaban.

Pero, esta convergencia se alargaba y dificultaba al continuar Chile con un proceso de desgravación unilateral, que llevaría su nivel mínimo a sólo un $6 \%$ como tope en el año 2003, y al seguirse realizando negociaciones de manera individual con diferentes países y pactos de integración. Idea en la cual se insistía. «Es posible -expresó el ministro de Hacienda, Nicolás Eyzaguirre- plantearse la incorporación plena al Mercosur, aun manteniendo por algún tiempo divergencias en la política de aranceles y algún grado de autonomía en la política de negociaciones internacionales" (13/07/00).

La misma idea fue defendida por el director económico de la Cancillería, Osvaldo Rosales. «Estamos convencidos -manifestó- de que el único mecanismo para seguir creciendo a una tasa alta y estable es seguir profundizando nuestra inserción internacional, tanto a nivel de la rebaja unilateral de aranceles, que llegará a $6 \%$ el año 2003, como por el hecho de persistir en tratativas de acuerdos comerciales con grandes mercados relevantes, como la Unión Europea y EE.UU., si se da el fast track» $(27 / 08 / 00)$. 
En junio de 2000, el arancel efectivo promedio de Chile se bajó a 6,6\%, con un gravamen general de $9 \%$, al considerarse los impactos de los diferentes acuerdos de libre comercio suscritos. Los productos provenientes del Mercosur fueron gravados en promedio en un 3,7\%. Nicolás Eyzaguirre estimó en ese momento que la «convergencia arancelaria» tomará más de cinco años para materializarse y quizás, agregó, 8 a 10 años (15/07/00).

En cuanto a las exportaciones chilenas al Mercosur, ya hacia el año 2001 -de acuerdo a antecedentes entregados por el jefe del Departamento de Comercio Exterior del Ministerio de Economía, Roberto Paiva durante el año 2000-aproximadamente el $70 \%$ de la oferta exportable chilena tendría arancel cero. La desgravación general terminó el año 2003 y dos años después, o sea el 2005, se concreta la apertura de productos «sensibles" $\mathrm{y}$ «sensibles especiales», como los textiles.

El Mercosur es un tratado de integración de enormes posibilidades, por su dimensión y la comunidad de intereses entre sus países miembros y asociados. Para Chile es la vía más lógica de construir acuerdos internacionales con otros países o regiones. El comercio entre sus miembros se ha multiplicando. La zona común reúne el $40 \%$ de toda la población latinoamericana. El Mercosur constituye a futuro un mercado de la mayor importancia para las exportaciones chilenas.

Sin embargo, no puede tenerse una visión idílica sobre el proceso, pensando en que con los acuerdos de libre comercio "todos ganan" -como señaló el presidente Lagos (14/07/00)- y que sólo existen beneficios y no costos. Si se examinan las cifras desde cuando se puso en vigencia el acuerdo de asociación entre Chile y el Mercosur hasta la fecha los intercambios comerciales ampliaron el déficit comercial del país, en más de cuatro veces, pasando de US $\$ 902$ millones a US $\$ 4,185,2$ millones. Mientras las exportaciones chilenas descendían, las importaciones se duplicaban.

\section{Intercambio comercial Chile-Mercosur 1995-2003}

(Fuente: Banco Central. En millones de dólares)

\begin{tabular}{lllll} 
& 1995 & 1997 & 1999 & 2003 \\
Exportaciones & 1.775 & 1.861 & 1.520 & $1.225,6$ \\
Importaciones & 2.677 & 3.193 & 3.093 & $5.410,8$ \\
\hline Déficit comercial & -902 & -1.332 & -1.573 & $-4.185,2$ \\
\hline
\end{tabular}


De otra parte, debe considerarse que existe una disputa entre EE.UU. y la Unión Europea por ganar presencia en el Mercosur, zona donde en la deácada de los noventa tuvo lugar una violenta irrupción de inversiones desde el viejo mundo. En un foro organizado, a comienzos de julio de 2000, en Buenos Aires, por la Fundación Euroamérica, el ex ministro de Relaciones Exteriores del Reino Unido, Douglas Hurd, lo planteó con absoluta crudeza, recordando lo acaecido ya en el comercio entre la UE y México. "La decisión de México como parte del TLC -señaló- ha producido un grado de integración con EE.UU. a una velocidad que nos ha sorprendido y ha producido una caída abrupta en el comercio entre México y la UE». La próxima batalla, agregó, será por el Mercosur. La disyuntiva es dramática, sentenció Hurd. O Europa compra los productos de Mercosur, o perderá influencia en la zona. "Si seguimos creando una fortaleza europea, no deberíamos sorprendernos de que suceda lo que pasó con México y que ésa [Estados Unidos] sea la opción de otros países" (05/07/00)

Una acción concertada regional puede permitir obtener ventajas de estas disputas y no quedar a merced de ellas. En la reunión de la Organización Mundial de Comercio de Seattle a fines de 1999 fue Brasil el que encabezó el bloque de las naciones en vías de desarrollo que criticó la posición de Washington, que tiene en el ALCA uno de sus pivotes a futuro.

"La integración de nuestros países -manifestó Fernando Henrique Cardoso en su discurso de bienvenida a un encuentro de presidentes efectuado en Brasilia- es un instrumento poderoso para enfrentar los desafíos de la globalización y para superar nuestras carencias y desequilibrios comunes. Debemos elaborar estrategias de desarrollo que incorporen una dimensión regional sudamericana". Una propuesta muy importante en esta dirección es establecer en el más breve plazo, las bases para un acuerdo de libre comercio entre el Mercosur y la Comunidad Andina. Desde luego ello permitiría enfrentar de otra manera las negociaciones del ALCA, acuerdo que se piensa poner en marcha el 2005.

"Una Sudamérica unida en un solo bloque ascendería a más que la suma de sus partes y en consecuencia estaría en posición de insistir en negociaciones más equilibradas con el bloque comercial de Norteaméricas, indicó con razón Gilberto Dupas del Instituto de Estudios Avanzados de la Universidad de Sao Paulo (31/08/00), comentando la citada reunión de presidentes. Esta estrategia se encuentra objetivamente en contradicción con la decisión del gobierno chileno de buscar por separado un acuerdo con EE.UU.

La acción común de países en desarrollo se reforzó en la Cumbre de Cancún de la OMC, efectuada en los últimos meses del 2003. La cumbre fracasó, repitiéndose lo acontecido en Seattle a fines de 1999, aunque en esta oportunidad EE.UU. y la 
UE actuaron en lo fundamental de acuerdo. Su fracaso se precipitó al intentar imponerse los llamados "temas de Singapur", los cuales se encuentran reflejados nítidamente en el TLC suscrito por Chile con EE.UU..

Durante la cumbre y en su fase preparatoria, el tema central de discusión giró en torno a los abultados subsidios agrícolas de las grandes potencias económicas, que favorecen en lo fundamental a grandes empresarios, que tienen un elevado poder de presión. Sin embargo, el quiebre no se produjo por este motivo sino cuando se intentó introducir en las resoluciones los "temas de Singapur": protección de la inversión extranjera, retomándose la idea de establecer el Acuerdo Multilateral de Inversiones; garantías para la libre competencia, es decir, abrir más las economías de los países en desarrollo; transparencia de los concursos públicos, o sea, permitir a empresas de otras naciones el acceso a las compras gubernamentales; y darle más relevancia a la defensa de los principios de propiedad intelectual, en otras palabras fortalecer el monopolio de quienes poseen el control de los avances científicos y tecnológicos.

Para EE.UU. lo central en su estrategia es imponer sus pretensiones en materia de servicios e inversiones. "El único rubro que tiene excedentes en la balanza comercial norteamericana respecto de América Latina -ha manifestado el abogado y economista de Flacso, Enrique Arceo- es el de servicios. Esto significa abrir la educación, la salud y el servicio bancario a la inversión de Estados Unidos, sin trabas de ningún tipo y con garantías absolutas. Esto implica -agregó- controlar a los Estados por las medidas que puedan poner sobre los inversores. Desde 1948 -enfatizó Arceo, Estados Unidos viene bregando por ampliar el concepto de «mercado de libre comercio" a la negociación sobre el «acceso a los mercados de servicios, protección de la inversión y de la propiedad intelectual. Esto constituye -concluyó el economista de Flacso- bajo la forma de desregulación” (13/10/03).

«En la base de todo el debate está la convicción liberal -escribió a su turno en "El País", José Vidal-Beneyto- de que la desregulación económica y la intensificación de un comercio sin barreras son garantía de crecimiento y de aumento de nivel de vida. Esta creencia -agregó- no ha sido nunca probada. ¿Por qué no proceder, pues, como sugiere el Consejo Económico y Social francés, a un balance público y contradictorio de las consecuencias para las poblaciones concernidas de las liberalizaciones de los últimos 20 años?» (13/09/03). Más bien la verdad es que los datos estadísticos refutan esta convicción, pues las brechas han continuado creciendo. Los niveles de crecimiento económico, durante los años de vigencia del modelo neoliberal, son menores a los alcanzados en los años anteriores. La brecha entre países ricos y pobres se ha ampliado y lo mismo acontece al interior de cada uno de ellos. La desigualdad en la distribución del ingreso continúa siendo el problema económico y social más grande. 
En Cancún, el «temario de Singapur» se presentó por las grandes potencias como una compensación frente a algunas concesiones a efectuar en el terreno agrícola, pretendiendo de esta manera en definitiva nuevas ventajas para los capitales transnacionales. Estas formulaciones se encuentran presentes en los acuerdos económicos suscritos con distintos países por EE.UU. y la UE, incluyendo desde luego los alcanzados con Chile. Por ello, como señaló la canciller Soledad Alvear, «Chile no tiene problemas en discutir ninguno de los cuatro puntos de la agenda de Singapur. Por ejemplo -agregó-, en materia de compras públicas hemos llegado a acuerdos en los Tratados de Libre Comercio que hemos firmado» (15/09/03), desde luego recogiendo la exigencia de la Casa Blanca.

En Cancún se expresó el malestar y la protesta de los países en desarrollo por estos magros avances y se colocó como prioridad precisamente el desarrollo, entendiendo como tal, acuerdos que vayan en beneficio de todos y, en particular de las naciones que tienen una posición desmedrada en el comercio mundial.

En la cumbre de la OMC se produjo un hecho nuevo: ya no se alcanza acuerdo como en un pasado no tan lejano cuando convergen las grandes potencias, particularmente EE.UU. y las naciones europeas más poderosas, tal cual aconteció durante medio siglo con el GATT. Ahora, existen nuevos actores pesando en la adopción de las resoluciones.

Se gestaba una nueva correlación de fuerzas. En 2003, nació el BRIC -de acuerdo a la sigla creada por Goldman Sachs-, cuarteto formado por Brasil, Rusia, India y China llamado, según el banco de inversión estadounidense «a constituir en pocas décadas señales de poder económico y territorial significativo" (21/06/04). El Mercosur se asocia a este bloque a través de Brasil. ¿¿Tiene presente la política internacional chilena esta nueva realidad? El ubicarse en forma acrítica junto a EE.UU. indica que no.

"En Cancún -como manifestó el presidente de Brasil, Lula da Silva-, ocurrió una novedad extraordinaria: cambió nuestra relación con el mundo desarrollado" (16/ 09/03). Durante la cumbre fracasaron los esfuerzos de la Casa Blanca de influir sobre China, Brasil y Sudáfrica para debilitar la posición conjunta. Obviamente, sus esfuerzos van a continuar.

Meses antes, en Evian, durante el desarrollo de la reunión del G-7, Brasil, India y Sudáfrica decidieron dar forma a un nuevo grupo denominado G-3 y se establecieron relaciones en la misma dirección con China y Rusia. La relación busca llegar más lejos. «Se trata de conseguir -ha enfatizado Celso Amorin- un mayor equilibrio en el mundo de hoy. Estamos negociando -manifestó el canciller brasileño- acuerdos de libre comercio entre el Mercosur y África del Sur, y también con India y 
eventualmente con países que formen parte de un área de comercio del Sur de Asia". Brasilia consideró necesario, acertadamente, agrupar más fuerzas para discusiones que se desarrollan paralelamente a nivel mundial. «Brasil -ha declarado su canciller, Celso Amorin- tiene una política exterior que es contraria a cualquier tipo de hegemonía o a la persecución de un liderazgo o algo así, pero, por otra parte, al ser una economía muy importante en la región tiene también sus responsabilidades. Nuestra primera prioridad es el Mercosur, y más ampliamente, América del Sur. Otro aspecto muy importante -agregó- es la relación con otros grandes países en desarrollo, que tienen problemas, y algunas veces soluciones, similares a las nuestras. Citaría -explicitó Amorina Rusia, China, India y Africa del Sur, entre otros» (22/07/03).

Construir este entendimiento tiene directa relación con la determinación de trasladar a la OMC -y no hacerlo en el marco del ALCA- temas considerados sensibles. «Los temas más sensibles y que representarían obligaciones nuevas para Brasil como la parte normativa de la propiedad intelectual, servicios, inversiones y compras gubernamentales -escribió Amorin- serían transferidos a la OMC, a ejemplo de lo que reclaman los EE.UU. en relación a los temas que les son más sensibles, como subsidios agrícolas y reglas antidumping” (29/07/03). Esta conducta es diametralmente distinta a la seguida por Chile, que aceptó negociar con Washington dejando de lado los temas "sensibles" para EE.UU. y poniendo en discusión todos los restantes aspectos, en condiciones absolutamente desiguales y no considerando los acuerdos y alianzas que se podían construir a nivel mundial.

«Nosotros -destaca Amorin- ponemos mayor énfasis en la integración de América del Sur, no en contraste con América Latina: a corto y medio plazo, lo único que se puede integrar es América del Sur. Queremos consolidar el Mercosur y ampliar los acuerdos del Mercosur con los otros países de América del Sur» (13/10/03). Ello muestra, desde otro ángulo, la posición diferente, adoptada por Chile al privilegiar en los hechos la alianza con EE.UU. y debilitar el frente regional.

El G-20 plus -destacó The Wall Street Journal- «incluye varios países normalmente vinculados a EE.UU. en asuntos comerciales, como Sudáfrica y Chile, con quien EE.UU. firmó un acuerdo de libre comercio" (11/09/03). Chile coincidió con el G-20 plus fundamentalmente en torno a la eliminación de los subsidios agrícolas. La formación de este grupo muestra la importancia que tendría si en América del Sur surgiese un frente común en las negociaciones hacia el ALCA, del cual Chile en la práctica se restó, al suscribir el TLC con EE.UU..

En la discusión de Cancún sobre los subsidios agrícolas se incorporó a un borrador de acuerdo algunas de las formulaciones del G-20. Sin embargo, el problema central continuó sin resolverse. «El total de los subsidios que los países ricos ofrecen 
a sus agricultores -ha señalado el presidente del Banco Mundial, James Wolfensohnsobrepasa el Producto Interno Bruto (PIB) de Africa, mientras el apoyo total a los agricultores de la Organización para la Cooperación y el Desarrollo Económico (OCDE) supera en seis veces el nivel de la ayuda extranjera" (12/09/03).

EE.UU. y la UE representan el 52\% del mercado global de alimentos, pero lo obtienen apoyándose en subsidios ascendentes a US $\$ 320.000$ millones anuales. Así aumentan artificialmente la competitividad de sus producciones agrícolas a costa de desplazar a productores de países en desarrollo. Estos subsidios tha señalado el canciller argentino, Rafael Bielsa- aumentan los ingresos de los productores «de manera escalofriante, como es el caso del arroz (casi 400\%), leche (más de 90\%), azúcar (90\%), trigo (57\%). La consecuente sobreproducción deprime los precios internacionales $y$, en definitiva, los productores eficientes no pueden competir en un pie de igualdad frente a esta realidad» (14/10/03).

Las consecuencias sociales de estos subsidios son muy grandes, dado que en definitiva estimulan en las potencias que los conceden, un alto nivel de autoabastecimiento que, como manifestó también el canciller transandino, «desplaza o impide las posibilidades de exportación de los países en desarrollo que no utilizan subsidios». De las 1.200 millones de personas que viven en el mundo con menos de dos dólares diarios, 900 millones, las tres cuartas partes, son pequeños campesinos de naciones en desarrollo. De las 800 millones de personas que padecen de hambre, paradojalmente, el $75 \%$ vive en zonas rurales.

Por tanto, el tema de los subsidios agrícolas tiene una directa relación con la desigualdad en la distribución del ingreso, el hambre y la pobreza a nivel mundial. Los organismos internacionales, y desde luego la $\mathrm{OMC}$, tienen una gran responsabilidad en ello, al resolver sistemáticamente políticas en beneficio de las grandes potencias económicas. En la Ronda Uruguay, que puso fin en 1994 al GATT y estableció la OMC, el tema agrícola se dejó de lado. Han transcurrido desde entonces diez años de existencia de la Organización Mundial de Comercio y los subsidios agrícolas se han elevado.

En Cancún se expresó la oposición de llegar a acuerdos si no se dejan de lado los subsidios agrícolas. La experiencia muestra los efectos negativos que estos subsidios causan en países que han suscrito acuerdos de libre comercio con EE.UU., experiencia que Chile no consideró. Así acontece, por ejemplo, con los productores de maíz mexicanos. Estudios de Oxfam cifran en más de US $\$ 10.000$ millones anuales los recursos entregados en EE.UU. a productores de este grano, "básicamente escriben Ignasi Carreras y Gonzalo Fajul, de Oxfam- terratenientes y grandes gigantes agroalimentarios. Al Sur del río Grande, en cambio -agregan-, quince millones 
de mexicanos se han visto golpeados por la caída de precios del maíz en un 70\% desde 1994, cuando entró en vigor el Tratado de Libre Comercio de América del Norte» (09/09/03). No han podido resistir frente a precios de dumping, que México no impugnó, al igual que Chile, al suscribirse el TLCAN.

Cancún incide directamente sobre las negociaciones hacia el ALCA, ya que son varios los temas que sobrepasan la esfera americana y que allí fueron cuestionados. «En las discusiones para crear el ALCA -manifestó el ministro de Agricultura de Brasil, Roberto Rodrigues-, los norteamericanos sólo aceptaron discutir la política de subsidios en la Organización Mundial de Comercio. Como consecuencia -agregó-, el Mercosur decidió también discutir en la OMC temas como compras gubernamentales, servicios e inversiones" (16/09/03). Ahora bien, dado que la OMC vio retardado su proceso de discusión se posterga también resolver sobre temas que influyen en el ALCA.

"Como lo ha demostrado la reunión de Cancún -ha escrito el economista de la Flacso, Roberto Bouzas-, los países desarrollados parecen poco inclinados a hacer concesiones sustantivas en temas sensibles en el marco multilateral. Parece aún más improbable -agregó- que las vayan a hacer en el contexto de negociaciones preferenciales del tipo Norte-Sur». De allí la necesidad de «mantener» el grupo de los $22^{1}$ y «consolidar las bases regionales de esa alianza más amplia» (22/09/03). La inserción de Chile en estos procesos presenta serias contradicciones por su determinación de privilegiar el acuerdo con EE.UU. y los compromisos adquiridos en el tratado suscrito.

Los «temas de Singapur» se encuentran en la filosofía de los acuerdos de «libre comercion impulsados por la UE y EE.UU.. La Casa Blanca, fracasada la cumbre, se propuso seguirlos impulsando mediante negociaciones bilaterales en donde, como también lo muestra el tratado con Chile, lleva todas las de obtener resultados favorables para su política, dada la desigualdad en que ellas se realizan. «Ante la falta de acuerdo -manifestó el representante comercial de la Casa Blanca, Robert Zoellick, al término de las deliberaciones- voy a abrir mercados país por país» (09/09/03), táctica que es la puesta en práctica en la región. Nuestra estrategia comercial, agregó, «tiene múltiples frentes. Tenemos tratados comerciales con siete países y estamos negociando con otros» (16/09/03).

«He tomado nota de las posiciones de muchos países de la OMC -manifestó a su turno el presidente del comité financiero del Senado norteamericano, Chuck Grassley- y cuáles han sido constructivas y cuáles no; sobre esta base, EE.UU. eva-

El número de países miembros se fue modificando, de allí sus distintas denominaciones: G-20, G-22, G-20 plus, etc. 
luará la posibilidad de nuevos acuerdos de libre comercion (16/09/03). Su tendencia es al bilateralismo, como camino a un acuerdo general. Por su parte, el comisario de Comercio de la UE, Pascal Lamy, conocido defensor del multilateralismo habló de la necesidad de una "reflexión" para decidir si ese sigue siendo el camino acertado (17/09/03).

Es decir, Washington decidió intensificar sus esfuerzos por acuerdos bilaterales, que le resulta el terreno más propicio y que es que se intenta implementar desde que se lanzó, a comienzos de los noventa, la llamada "Iniciativa para las Américas». En Cancún, sufrió un traspié al avanzar hacia una mayor apertura comercial y al movimiento de capitales por vías multilaterales. Por eso, la táctica de la Casa Blanca de tratar nuevamente de hacerlo avanzar a través de acuerdos bilaterales. De allí la importancia de intensificar el entendimiento de los países latinoamericanos entre sí $\mathrm{y}$ con aquellas naciones que permiten levantar a nivel mundial posiciones comunes, que es el camino para hacer fracasar la táctica de la Casa Blanca..

La octava ronda de negociaciones del Acuerdo de Libre Comercio de las Américas (ALCA), efectuada en noviembre de 2003 en Miami, finalizó un día antes de lo previsto -para impedir nuevas manifestaciones masivas condenatorias, como aconteció en varias reuniones de organismos internacionales- con una resolución calificada de "light" o "descafeinada", ya que los principales puntos de divergencia se postergaron para ser abordados muchos de ellos en el marco de la Organización Mundial de Comercio (OMC). "Es un paso importante -manifestó el representante comercial de EE.UU., Robert Zoellick, finalizada la cita-, pero ahora entramos en un momento decisivo en el que no faltarán las dificultades» (22/11/03).

La Casa Blanca debió dejar transitoriamente de lado su propósito de establecer plenamente y en el conjunto de la región, su concepción de la integración regional que expresa en forma fiel y profundizada las concepciones del Consenso de Washington, ante la decidida resistencia de Brasil, Argentina y Venezuela, dando lugar a lo que se definió como un acuerdo «a la carta", ya que cada país determina su grado de integración. El 1 de enero de 2005 sigue siendo la fecha estipulada para que el ALCA entre en vigencia, ahora en esta versión de diferentes niveles de inserción. Es un contexto claramente diferente al existente en la Cumbre de las Américas de 1994 que, lisa y llanamente, pretendía extender el Tratado de Libre de Comercio de América del Norte al resto del continente.

Los aspectos controvertidos -entre ellos los subsidios agrícolas y los mecanismos norteamericanos antidumping, así como los capítulos de servicios, inversiones, normas de compras gubernamentales y protecciones de la propiedad intelectual- quedaron como opcionales. Constituyen el menú que cada país puede elegir, según el 
lenguaje empleado. Se establecieron dos niveles. En el primero existirá un conjunto de obligaciones y derechos "mínimos", un denominador común, y en el segundo se coexistirá con acuerdos bilaterales o regionales. Fue la fórmula construida para evitar un seguro fracaso del proyecto, que en principio se proponía la apertura hemisférica en forma plena para enero de 2005. Las divergencias y contradicciones continuaron planteadas.

En el párrafo séptimo de las resoluciones, los ministros establecieron que se pueden asumir "distintos niveles de compromiso" de acuerdo a las necesidades de los socios. Chile, conjuntamente con Canadá y México -es decir, los países que ya hicieron suyas a plenitud las formulaciones estadounidenses- defendieron la idea de que se estableciese en toda la línea las directrices originales de la Casa Blanca. El acuerdo no los satisface. La canciller chilena, Soledad Alvear, manifestó que «no es lo que esperaban, pero -admitió- representa la realidad de la región» (22/11/03).

Con su posición el Gobierno Lagos acentúa su distanciamiento objetivo de muchos Estados latinoamericanos, por privilegiar en todo momento el acuerdo y las posiciones de la Casa Blanca. "La evolución de las relaciones con la región -constató editorialmente "El Mercurio" (21/11/03)- está causando preocupación. Algunos analistas -precisó- destacan el estrechamiento de los vínculos con Norteamérica, Asia y la Unión Europea y los contrastan con los desencuentros con países de la región». La verdad es que no son "desencuentros» sino políticas diferentes, como se demuestra en un tema tan determinante como son los procesos hacia el ALCA.

EE.UU., actuando con pragmatismo y consciente que no estaba en condiciones de imponer su recetario, optó por el acuerdo «a la carta», pero manteniendo su determinación, ya expresada al finalizar la fracasada cumbre de Cancún de la OMC, de ir imponiendo su esquema a través de entendimientos bilaterales. «Creemos enfatizó Zoellick- que profundizar las relaciones bilaterales es la vía para completar con éxito las negociaciones del ALCA» (19/11/03). Trata de hacer jugar a su favor el hecho de representar más de un $80 \%$ del producto global de la región, ascendente a unos US\$13 billones. En otras palabras, la Casa Blanca coloca en primer plano la idea de acuerdos "país por país". El primer paso en este sentido fue el Tratado de Libre Comercio de América del Norte en el que incorpora a México, desgajándolo de América Latina. El segundo paso fue el TLC con Chile y el tercero el tratado con Centroamérica, acuerdo que en un principio se pensó sería fácil de obtener, sin embargo, posteriormente se postergó. En diciembre de 2003 se logró un acuerdo de libre comercio entre EE.UU. y cuatro de los cinco países centroamericanos, dándose así un paso importante hacia un TLC.

En el trasfondo de la falta de acuerdo subyace la oposición creciente en la región a las ideas del Consenso de Washington. El propio presidente de la OEA, César 
Gaviria, constató que la negociación se efectuó en un «entorno difícil» por la "preocupación que ha generado el neoliberalismon (20/11/03).

En el plano social, se vive en el Mercosur un cuadro de agravamiento de los problemas. Las tasas de desocupación -tal cual acontece igualmente en Chile- son muy elevadas.

El proceso de integración no puede avanzar sin considerar estas realidades. Debe buscar mecanismos para enfrentarlas. Las coordinaciones macroeconómicas deberían considerar políticas en estos aspectos y construir una estrategia de desarrollo basada en el interés de los pueblos del cono sur.

Los desafíos son grandes. El Mercosur es la vía indiscutida por donde deben avanzar los acuerdos de integración del país. Pero ello no significa que las negociaciones realizadas hasta ahora hayan sido en todos los planos las adecuadas y que toda convergencia macroeconómica que se concuerde será beneficiosa. En no pocos sectores el interés nacional no se resguardó. No puede perderse de vista que en los países del Mercosur y Chile predomina los mismos esquemas de política económica y se buscará remacharlos a través de acuerdos supranacionales. Se trata de temas que exigen un muy amplio debate nacional.

\section{Chile Privilegia Tratado con EE.UU..}

El presidente Lagos anunció a fines de noviembre de 2000 en EE.UU. -en acuerdo con el saliente mandatario estadounidense Bill Clinton- que se retomaban las negociaciones formales para llegar a un acuerdo de libre comercio entre ambos países, las cuales se iniciaron rápidamente el 6 de diciembre. Este objetivo se buscó insistentemente sin éxito durante las administraciones Aylwin y Frei, siendo ministros de $\mathrm{Ha}$ cienda Alejandro Foxley y Eduardo Aninat. Lo nuevo es que esta determinación se produjo luego de reiteradas declaraciones de Lagos y su equipo de gobierno de privilegiar la incorporación de Chile al Mercosur, perspectiva que con el paso dado se descartó explícitamente. Las tratativas se comenzaron a llevar adelante sin contarse con el mecanismo de "fast track», el cual garantiza el respeto de los acuerdos suscritos por un congreso norteamericano seriamente dividido después de las últimas elecciones. Llama la atención, igualmente, que el acuerdo se adoptó apresuradamente, a los pocos días de dejar Clinton su cargo y por iniciativa del presidente estadounidense.

En contradicción abierta con los hechos, la ministra de RR.EE., Soledad Alvear, sostuvo que el inicio formal de las negociaciones de libre comercio con EE.UU. no sería excluyente ni entraría en conflicto con otros tratados, los cuales -afirmó- serían complementarios $(04 / 12 / 00)$. Los hechos la desmintieron rápidamente. El canciller brasileño, Luis Felipe Lampreia, habló de "cambios en las prioridades de la 
política exterior del Presidente Lagos». El secretario ejecutivo de la Cámara de Comercio Exterior de Brasil, órgano gubernamental de la política exterior del mayor país sudamericano, Roberto Gianetti, manifestó que «la decisión de Chile nos dejó perplejos y frustrados porque estábamos dándole mucho valor a su ingreso en el Mercosur» y que se debería ser «intransigente» en demandar compensaciones (05/12/00).

La posición abiertamente crítica a la actitud del gobierno de Lagos se abandonó en la cumbre presidencial de Florianópolis, por la directa intervención del mandatario brasileño Cardoso, que reconoció el derecho de Santiago de iniciar conversaciones con EE.UU. «dadas las diferencias arancelarias existentes» (16/12/00). El gobierno chileno se comprometió a mantener informado al Mercosur de los avances en sus negociaciones con EE.UU., dejándose postergada para más adelante la incorporación al tratado regional.

«Somos un país pequeño -dijo Lagos en Florianópolis-, abierto al mundo. Ahora tenemos acuerdos comerciales con México y Canadá, y estamos negociando con Europa y EE.UU. No obstante nuestra preferencia política es el Mercosur" (16/12/ 00). Al anunciar el acuerdo con Clinton había señalado: "Queremos hacer una política exterior desde el Mercosur" (04/12/00). Es obvio que, para efectuar una política desde el Mercosur deben acordarse acciones conjuntas con sus países integrantes y no negociar separadamente con diferentes países y zonas económicas, en contradicción con acuerdos de la zona.

Los gobiernos del Mercado Común no fueron informados previamente del acuerdo con EE.UU. y conocieron la noticia de parte de personeros norteamericanos, a pesar que se trabajó el entendimiento durante varios días. Fue un golpe bajo al Mercosur. Más aún, cuando el presidente Lagos había manifestado expresamente que Chile estudiaba la posibilidad de solicitar antes de finalizar el 2000 la incorporación plena al tratado de libre comercio regional. Al llegar a acuerdo con Clinton, en cambio, descartó que Chile tenga prioridades, sosteniendo que el propósito es negociar con todos los bloques comerciales, sin opciones ni preferencias.

La decisión de solicitar la incorporación plena había sido ya abandonada expresamente en el mes de noviembre mientras se celebraba la X Cumbre Iberoamericana en ciudad de Panamá. Las diferencias de políticas y tarifas arancelarias llevaron a que los presidentes de Chile y de los países que integran el Mercosur -explicó el director general de Relaciones Económicas Internacionales de la Cancillería, Osvaldo Rosales- resolvieran dejar sin fecha el proceso que conducía a la incorporación de Chile al pacto subregional. Acuerdos previos entre las partes habían dispuesto dar vida a un proceso de negociación de convergencias, entre ellas arancelarias, para que Chile se integrara como quinto miembro del Mercosur. Sin embargo, una visión 
"más pragmática» de las dificultades que persisten para que dicha convergencia se haga una realidad -agregó Rosales-, llevaron al Presidente Ricardo Lagos a plantear en una cena con sus pares del bloque la conveniencia de eliminar plazos. Detrás de la postura del Mandatario -agregó Rosales- está la insistencia del Mercorsur de coartar la autonomía para que Chile negocie por separado diversos acuerdos comerciales con terceras naciones $(21 / 11 / 00)$.

Los hechos mostraron a los pocos días que se había privilegiado una vez más el acuerdo bilateral con EE.UU., tal cual lo hicieron antes los gobiernos de Aylwin y Frei. Osvaldo Rosales indicó que este tratado pasaba a ser la prioridad de la política comercial durante el año $2001(22 / 12 / 00)$.

La decisión constituyó un triunfo del gobierno norteamericano interesado en debilitar el Mercosur para abrir camino a procesos de integración bajo su hegemonía, en particular a través del ALCA. El gobierno chileno se prestó para ello. La representante comercial a esa fecha de EE.UU., Charlene Barshefsky, no lo ocultó, manifestando expresamente que detrás del repentino interés del gobierno Clinton está estimular y servir de ejemplo al ALCA. En esta idea coincidió la canciller chilena Soledad Alvear. Su instauración significó, obviamente, la desaparición en definitiva del Mercosur.

Una política efectivamente desde el Mercosur permitiría crear una mejor correlación de fuerzas para negociar posteriormente con EE.UU. o la Unión Europea. En este sentido, la reunión cumbre de presidentes sudamericanos efectuada en Brasil en agosto de 2003 fue un esfuerzo por forjar un frente regional unificado en las negociaciones con Estados Unidos en el tema de una zona de libre comercio hemisférico.

Una negociación Chile-EE.UU., en cambio, es absolutamente desigual. El país del norte tiene un producto varias veces superior al chileno con un desarrollo científicotecnológico y niveles de productividad incomparablemente más elevados. Para EE.UU. la importancia del Tratado es esencialmente política y apoya su estrategia regional, mientras en la economía chilena tendrá fuertes repercusiones directas negativas.

«La contrapartida, que es la entrada recíproca de manufacturas -establecida en los acuerdos de libre comercio tipo ALCA, como destacó Le Monde Diplomatique $\left(\mathrm{n}^{\circ} 2\right)$ - se parece mucho a una cláusula de los tratados del siglo XIX entre Inglaterra y Argentina, que fijaba el criterio igualitario que la flota inglesa podía navegar libremente en los ríos argentinos y la flota argentina en los ríos británicos. Sólo que la flota argentina no existía».

La magnitud del mercado norteamericano fue presentada por los propagandistas del acuerdo de libre comercio con EE.UU. como una gran opción para las exporta- 
ciones chilenas. Se perdía de vista que el arancel promedio pagado por los productos chilenos al ingresar a EE.UU. era de apenas $0,9 \%$, como lo constataba Osvaldo Rosales. De otra parte, varios productos chilenos entraban al mercado norteamericano aprovechando el Sistema de Preferencias Arancelarias y, en consecuencia, se colocaban libres de impuestos.

Desde luego, en todo acuerdo de libre comercio existen beneficiados, ellos se encuentran entre productos de mayor valor agregado. EE.UU. es un país que tiene una estructura arancelaria y paraarancelaria orientada a proteger a su producción interna, mientras entrega facilidades al ingreso de aquellos recursos primarios que requiere. Pero, como manifestó el economista de la Universidad de Chile, Manuel Agosín, si bien hay productos beneficiados «los efectos serían marginales» (04/12/ 00). Hasta ahora es así. En los primeros cinco meses de 2004, las exportaciones a EE.UU. aumentaron, con relación al año anterior, en sólo 2,5\%. Sin duda que en definitiva deben crecer en magnitudes mayores, pero no se cumple lo aseverado por los panegiristas del tratado.

Paralelamente, debe considerarse que en un acuerdo bilateral el intercambio es bidireccional. Al eliminarse protecciones vigentes en la economía chilena para los productos estadounidenses se multiplica el ingreso de bienes desde una nación incomparablemente más poderosa. Todos los estudios realizados sobre un acuerdo de libre comercio entre Chile y EE.UU., incluso los efectuados por partidarios del Tratado, concluyen que el intercambio crecerá principalmente hacia el país, implicando un nuevo golpe para la producción de bienes transables orientados al mercado interno, que ya sufrían antes de suscribirse el TLC las consecuencias de los procesos de apertura comercial. Ya en 1993, Juan Eduardo Coeymans y Felipe Larraín establecieron que si se estudiaban los efectos a largo plazo de un acuerdo de libre comercio Chile-EE.UU. el quantum de las exportaciones desde el país crecería en $17,99 \%$, mientras que el de las importaciones lo haría en $31,19 \%$.

Estudios recientes lo confirman. Un análisis realizado por la Comisión de Comercio Internacional de EE.UU., preparado a encargo del gobierno Bush -titulado "TLC Estados Unidos - Chile: efectos potenciales para toda la economía y para sectores seleccionados", concluyó que las exportaciones estadounidenses serán significativamente más favorecidas en el intercambio mutuo, dado que aumentarán a un ritmo cuatro veces superior a las efectuadas desde Chile. Por tanto, EE.UU. es el gran beneficiado en el intercambio comercial en oposición a lo sostenido por la canciller Soledad Alvear en el sentido que el tratado tendrá un mayor impacto en las exportaciones chilenas hacia ese destino que en los envíos norteamericanos hacia nuestro país (21/08/03). 
El estudio cifrando el efecto comercial estima que las exportaciones desde EE.UU. hacia Chile en el año 2016 -cuando termina el proceso de desgravación arancelariade no existir tratado alcanzarían a US $\$ 5.697$ millones, creciendo en $80 \%$, y al suscribirse el TLC aumentarían adicionalmente entre $18 \%$ y $51,7 \%$, fluctuando entre US\$5.615,4 millones y US\$6.395 millones. Por su parte, las ventas desde Chile crecerían sin tratado en $70 \%$, incrementándose al suscribirse el acuerdo sólo entre $5,7 \%$ y $13,7 \%$, moviéndose entre US $\$ 5.832$ millones y US $\$ 6.019,7$ millones al año 2016. Se muestra que el crecimiento anual de las ventas desde el país es más reducido, mientras que por el contrario es más fuerte el ingreso desde EE.UU., lo cual obviamente conduce a acentuar el proceso de sustitución de producción nacional por importaciones. De esta manera, el actual saldo comercial positivo que tiene para Chile el intercambio bilateral se transformaría en negativo.

La asimetría en el movimiento comercial tiene varias explicaciones. Una de ellas reside en que la reducción arancelaria efectuada por Chile, al momento de suscribirse el tratado, fue muy superior a la realizada por EE.UU., dado el diferente nivel impositivo existente en cada país en el intercambio mutuo. Las ventajas de un tratado comercial de reducción arancelaria, son inversas a los gravámenes existentes y sucede que mientras los de Chile eran de $6 \%$ los cobros efectuados en EE.UU. eran menores al $1 \%$. Si EE.UU. ya tenía un promedio arancelario bajo para las exportaciones chilenas y no se experimentará una reducción significativa de ellos, es claro que es Chile quien entrega concesiones mayores.

De otra parte, debe tenerse en consideración la vigencia del Sistema General de Preferencias Arancelarias norteamericano que permite desde hace años el ingreso de determinados productos nacionales sin pagar aranceles. En consecuencia, los bienes que se exportan desde Chile por este conducto no experimentarían beneficios arancelarios, teniendo como ventaja que la actual determinación unilateral de EE.UU. deja de serlo, se consolida.

El arbitrario mecanismo antidumping, vigente desde 1916, puede ponerse en movimiento en cualquier momento, lo cual convertirá en una ficción el «libre comercio». La vigencia ya durante una década del TLCAN muestra que EE.UU. recurre constantemente a medidas paraarancelarias de tipo proteccionista. Los ejemplos abundan. Cuando hubo una temporada agrícola con fuertes heladas que afectó las producciones de tomates de California y Florida, produciéndose un incremento en sus costos, el gobierno norteamericano exigió que México estableciese un precio mínimo de US\$0,15 por libra o, lisa y llanamente, la exportación a EE.UU. no podría concretarse, para defender la producción interna. México estableció «soberanamente» el piso mínimo. De igual modo, transcurrieron más de cinco años, 
desde que entró en vigencia el TLCAN para que los camiones mexicanos pudiesen llegar al lugar de destino de los productos exportados. Durante esos años se les impidió mediante diferentes subterfugios.

Igualmente las conclusiones de los diferentes estudios muestran que el efecto principal no se producirá en el plano del comercio exterior sino en el de las inversiones. Su crecimiento fue uno de los aspectos destacados por el presidente Lagos el día de su anuncio. Pero, los hechos muestran que la inversión no puede analizarse en general, sino que en concreto, diferenciando entre aquella que es positiva para el país y otra que no sólo dista de tener ventajas sino que es abiertamente inconveniente, como lo es la orientada a apoderarse de recursos naturales o de empresas en funcionamiento controladas por capitales nacionales o, lisa y llanamente, la que ingresa con fines especulativos. De igual modo, debe evaluarse el menor atractivo que para determinados inversionistas tiene la no incorporación al Mercosur.

El acuerdo con EE.UU. actualizó muchos otros temas trascendentes. Entre ellos la conocida exigencia norteamericana -en plena coincidencia con los intereses del gran capital- que no se coloque ningún tipo de restricciones a los movimientos de capitales; el reforzar a un nivel superior los derechos de propiedad intelectual, lo cual intensifica la posición preponderante en muchas esferas de los grandes consorcios estadounidenses; la precariedad en el país de los derechos laborales; la insuficiencia de las políticas nacionales medioambientales; y la casi nula participación de la sociedad civil en estos procesos de discusión.

En algunos de estos temas se produjeron divergencias desde un primer momento. Así sucedió con los temas medioambientales y laborales definidos por la Representante Comercial de EE.UU., Charlene Barshefsky, de «asuntos cruciales» (08/ 12/00). El comunicado de la Casa Blanca habló que la negociación con Chile siguió el convenio suscrito en el curso del año 2000 con Jordania, en el cual se establecieron sanciones comerciales para los incumplimientos en estas esferas. En cambio, los documentos oficiales chilenos se propusieron seguir el acuerdo del tratado bilateral con Canadá, donde las partes se comprometen en lo fundamental a respetar sus propias legislaciones. ¿Y que pensaban sobre estos temas las organizaciones sindicales y la sociedad civil? Este fue el criterio que finalmente se impuso.

Chile requería contar con una política comercial internacional clara, que no descanse en mantener negociaciones paralelas con cuanto gobierno de cualquier lugar de la tierra le proponga alcanzar un acuerdo de libre comercio, sino en función de tener una visión en concordancia con los intereses nacionales de cómo incorporarse a los procesos de integración. Debía tenerse un plan estratégico en materia de relaciones económicas internacionales y éste debía privilegiar realmente 
la incorporación plena al Mercosur, a pesar de sus contradicciones y problemas existentes y profundizar las relaciones con el conjunto de los países latinoamericanos. Se trata de un grupo de países con identidad de situaciones y problemáticas, reforzadas por la cercanía geográfica y en los cuales predominan políticas en $\mathrm{mu}$ chos terrenos más que discutibles, que establece también la necesidad de profundizar sobre la dirección que adquieran los procesos de convergencia macroecómica iniciados. No se siguió este camino.

\section{La Moneda Alineada Junto a EE.UU. tras el ALCA.}

La reunión preparatoria de la cumbre de Miami del Área de Libre Comercio de las Américas (ALCA) realizada en Trinidad Tobago, en octubre de 2003, fracasó, al igual como aconteció con la cita de la Organización Mundial de Comercio (OMC) en Cancún. Las razones de ambos fracasos fueron similares. En Trinidad Tobago, EE.UU. no aceptó poner en discusión su sistema de subsidios agrícolas -que distorsiona el comercio mundial y perjudica a producciones de muchos países, entre ellos Chile-, al tiempo que se esforzó por introducir acuerdos sobre liberalización de los mercados de capitales y la protección plena a las inversiones extranjeras.

La oposición a los propósitos norteamericanos fue encabezada en la región por Brasil y Argentina, los cuales manifestaron que si la Casa Blanca no quería poner en el debate la temática de los subsidios agrícolas dejándolo para su consideración en la OMC, otro tanto debía hacerse con la apertura en el movimiento de capitales, así como con la propuesta estadounidense que las adquisiciones gubernamentales sean efectuadas en licitaciones internacionales y con el otorgamiento de mayores garantías a los inversionistas extranjeros. «Si los norteamericanos pueden sacar de la agenda los temas sensibles para el gobierno de George Bush -replicaron los representantes de ambos países-, también el Mercosur tiene derecho a eliminar aquellos asuntos que consideran vitales para sus economías» (04/10/03).

Los fracasos de las reuniones de Cancún y Trinidad Tobago llevaron a EE.UU. a intensificar la búsqueda de acuerdos bilaterales. Para ello presiona a los países de la región que en Cancún se incorporaron al grupo denominado 20 plus, buscando que lo abandonen.

En Trinidad Tobago, la representación de la Moneda se ubicó claramente junto a la Casa Blanca. Ello no tiene nada de raro si se considera que aceptó suscribir el acuerdo de libre comercio sin poner en discusión los subsidios agrícolas norteamericanos y su mecanismo antidumping -a pesar de pronunciarse en contra de ambos en numerosas reuniones internacionales- $y$ que todas las propuestas estadouniden- 
ses que llevaron al fracaso de la cita ya las aceptó al suscribirse el TLC bilateral. Además de Chile se colocaron junto a EE.UU., México (que igualmente ya incorporó estas mismas imposiciones en el Tratado de Libre Comercio de América del Norte) y Colombia, muy dependiente de EE.UU. por la vinculación que se produce en el llamado "Plan Colombia». Objetivamente, a pesar de las declaraciones en sentido contrario, el gobierno chileno se aleja, con esta posición, de los principales países latinoamericanos, privilegiando el acuerdo con EE.UU.. Más aún, representantes de la Cancillería chilena recorren diferentes países divulgando el acuerdo alcanzado con EE.UU. y, por tanto, en los hechos haciéndole propaganda al ALCA.

Mientras tanto en el Congreso chileno avanzaba la aprobación del Tratado con EE.UU. sin que se discutiese sobre los graves compromisos que conlleva y la realidad concreta en que se suscribe. Se aceptaba, por ejemplo, la absoluta liberalización de los movimientos de capitales sin tener presente, como recordaba en esos días el premio Nobel de Economía, Joseph Stiglitz, que ello conduce a que los países queden a merced de "los caprichos de los movimientos de capital internacionales" (04/ 10/03). «Incluso -agregó Stiglitz- sin la liberalización de los mercados de capital el mundo seguirá enfrentándose a una enorme volatilidad. Las crisis -enfatizó- no serán cosas del pasado». Con mayor razón, la volatilidad se producirá con la apertura plena de su mercado de capitales, como irresponsablemente aprueba Chile. La ligereza con que se aceptaron estas imposiciones es increíble.

El «Informe sobre el comercio y el desarrollo 2003", de la Conferencia de las Naciones Unidas sobre Comercio y Desarrollo (Unctad) constata a su turno que «se presiona más y más a los países en desarrollo para que observen una disciplina fiscal mayor, desregulen más los mercados y apliquen una liberalización aún más rápida, a pesar de que las perspectivas de crecimiento se han vuelto menos halagüeñas en muchos países y de que la pobreza ha aumentado" (06/10/03). El informe es crítico con las políticas económicas dominantes desde la década de los ochenta a través de las cuales se esperaba poner término al caos macroeconómico, a los debilitantes niveles de las deudas externas y abrir camino a una era de crecimiento sostenido y de reducción de la pobreza. En otras palabras, las políticas que insiste en impulsar EE.UU. no han dado resultado. Ellas son las que Chile suscribió con el TLC.

En el parlamento chileno, los temas levantados por EE.UU. que llevaron al fracaso de las reuniones de Cancún y Trinidad Tobago -y han agudizado contradicciones a nivel mundial- se tratan muy parcialmente y sólo por la movilización sectorial provocadas por los efectos en el agro de llegar a un acuerdo que acepta los subsidios agrícolas norteamericanos y coloca las producciones internas en abierta desventaja. «El fracaso de la reunión de Cancún -advierte Stiglitz- debería servir de advertencia: 
hay algo que funciona básicamente mal en la forma como se gestiona el sistema económico global. También hay algo que funciona básicamente mal -añadió- en el sistema económico mundial. ¿Cuántas crisis deben producirse -se preguntó, finalmente- antes de que se asimile esta dura verdad?». En Chile, en vez de asimilarla, se aceptan imposiciones que llevan a ellas.

\section{Crisis del Gas Confirma Aislamiento de Chile}

La realidad gasifera de la región fue generando entendimientos y alianzas en las cuales Chile nuevamente tendía a quedar aislado, tal como acontece en las reuniones hacia el ALCA. Brasil, Argentina, Bolivia y Venezuela estudian proyectos para unir sus actividades gasiferas y de combustibles. Brasil efectuó una propuesta en tal sentido a Argentina y a Bolivia, mientras el gobierno transandino analiza una iniciativa para asociarse a Petrobras y Petróleos Venezuela. The New York Times habló, refiriéndose a Chile, de "los chicos ricos del barrio que comienzan a sentirse solos" (29/04/04). La vía de los conflictos con los países vecinos no conduce a ningún lado.

Paralelamente, se va modificando la situación en países determinados. "Si pensamos en términos de 10 a 15 años -manifestó el ex gerente general de Enap, Daniel Fernández-, hay que pensar que países como Colombia, Argentina y otros, han ido pasando de productores y exportadores a importadores energéticos. Por tanto -recalcó Fernández- uno tiene que evaluar a futuro la diversificación de su fuente de abastecimiento" (18/04/04). El aislamiento político de Chile en la región dificulta que los cambios de abastecedores puedan efectuarse fácilmente.

La situación producida conlleva que la matriz energética prevista, en base al gas natural, debe necesariamente revisarse. "Todos estamos de acuerdo -manifestó el presidente de Corfo, Oscar Landarretche-, en que Chile no va a poder seguir desarrollando su programa hacia el futuro, aumentando la incidencia del gas natural» (30/04/04). Entre las iniciativas de diversificación se encuentra establecer un terminal que permita traer gas por barco y luego inyectarlo en el gaseoducto de Gas Andes. Este mecanismo es muy usado por Japón que consume el $70 \%$ del gas natural licuado mundial.

Significativamente, el aislamiento regional se produce cuando han transcurrido pocos meses del acuerdo con EE.UU. y se suponía que, como consecuencia de ello, la posición internacional de Chile se fortalecería. No fue así. El gobierno de Lagos optó por poner en primer lugar su alianza con la Casa Blanca y, por tanto, su apego a las orientaciones del Consenso de Washington, en momentos en los cuales las políticas neoliberales son fuertemente cuestionadas en la región. Varios gobiernos 
sudamericanos se desplazaron o están en vías de desplazarse hacia posiciones críticas al Consenso de Washington, como aconteció en Brasil, Argentina y Venezuela, y todo indica que sucederá próximamente en Uruguay. "Personeros de gobierno comentó en The New York Times, Larry Rohter, refiriéndose a Chile- sostienen que están conscientes de su imagen desigual y están tomando medidas para solucionar las diferencias con sus vecinos. Pero, sus iniciativas se han limitado al comercio, como enviar delegaciones a Brasil y Centro América, para aconsejar que se puede continuar en las negociaciones con EE.UU."(29/04/04). En otras palabras, han actuado de propagandistas del acuerdo suscrito con Washington y del ALCA, lo cual tiende a alejarlo más de los países de la región, con mayor razón cuando en ellos hay un profundo sentimiento en contra de este tratado.

Es preocupante que Chile tenga en estos momentos tan malas relaciones con sus países vecinos. En Bolivia estos hechos se unieron al tradicional sentimiento de critica al hegemonismo chileno, expresado fuertemente en la sublevación de octubre del año pasado y en la venta de gas a Argentina estableciéndose que no se puede reexportar a nuestro país. En la visión del udista Instituto Libertad y Desarrollo, en cambio, «es vital no quebrar los pilares fundamentales que han diferenciado a Chile del resto de las economías de América Latina». (25/06/04).

La gravitación del Estado argentino en el sector se redujo por la política de privatizaciones que alcanzó su máxima expresión cuando se traspasó Yacimientos Petroliferos Fiscales (YPF) al consorcio español Repsol, presente también en el país. La Secretaría de Energía transandina prácticamente no tiene atribuciones sobre las empresas privadas, sólo los transportistas y empresas distribuidoras están bajo un régimen de regulación. Una situación similar se ha producido en Chile en las áreas de servicio donde las antiguas empresas estatales fueron privatizadas.

De otra parte, el Gobierno argentino no cuenta con instrumentos que le permitan conocer los costos de las empresas, ni contar con cifras confiables de reservas, a pesar que los consorcios privados trabajan obras concesionadas. "Hoy son pocos los elementos con los que el Estado cuenta -reseñó Kirchner- después de haber perdido en la década de los noventa todas las herramientas macroeconómicas" (30/04/04). El Estado incluso perdió "la acción de oro" en YPF, que le permitía vetar decisiones fundamentales. La crisis de abastecimiento se desencadenó luego de un largo periodo de elevadas ganancias, muy altas en relación con los promedios internacionales, hecho que se tiende a olvidar cuando se analiza la situación de las empresas. Un proyecto del gobierno de Kirchner es crear una empresa nacional de energía, a través de la cual se avanzaría a una integración con las empresas estatales de Brasil y Venezuela, que el presidente Chávez bautizó como Petroamérica. 
De igual modo, disminuyó la importancia de Argentina en las importaciones chilenas de petróleo. El crudo traído de la nación transandina porcentualmente se redujo, de acuerdo a cifras entregadas por Enap, de $63 \%$ hace dos años a $48,25 \%$ en la actualidad. Ello obligó a Chile a incrementar sus adquisiciones desde otros países latinoamericanos, lo cual implica un costo mayor en transporte. Desde Argentina el envío es más barato porque existe un oleoducto desde Neuquén a Talcahuano.

Sugestivamente, uno de los anuncios de recorte en el suministro de gas se produjo inmediatamente después de una visita a Buenos Aires de la canciller Soledad Alvear, mostrándose así el fracaso de los esfuerzos diplomáticos efectuados. Llama la atención que el gobierno chileno siga concentrando sus críticas en la administración transandina y no en los transnacionales proveedoras que no están cumpliendo con sus contratos y están empujando en Argentina el precio del alza. Hace diez años, cuando se iniciaron las exportaciones a Chile se estableció el precio máximo, equivalente al combustible alterno. Este mismo precio quieren imponerlo progresivamente en Argentina. "La última jugada de Repsol -comenta Página 12- fue hacer desaparecer el gas. Es un misterio que en julio del 2003 -agrega la publicaciónhayan entregado 3.800 millones de metros cúbicos, en marzo de 2004 sólo 3.200, ¡y hayan estado cortándole la provisión a numerosas fábricas, cuando también sobra capacidad de transporte! Hace menos de medio año, las petroleras visitaban con humildad a los clientes y firmaban contratos por 73-75 centavos de dólar. Ahora no se consigue a menos de US $\$ 1,15$ y bastante menos de lo apetecido. En los contratos, que no incluyen compromiso firme de suministro, ya se establece un precio de US $\$ 1,40$ para el invierno de 2005. Ni el petrolero más optimista soñó con conseguirlo tan pronto" (03/05/04).

La región requiere de una integración energética. Los hechos muestran su necesidad. El ministro de relaciones exteriores de Uruguay, Divier Opartti, propuso en visitas efectuadas a Brasil y Chile la creación de un banco de energía "que significa -dijo- tener una disponibilidad energética en la región que permita solventar los déficit coyunturales". Ese "banco" -añadió- actuaría como "seguro" para evitar que se vuelvan a producir crisis similares a las que se están viviendo en varios países. Uruguay, al igual que Chile, fue afectado por recortes de gas desde Argentina. De la misma manera, se procedió a reducir las ventas de gas natural a Brasil. De actuarse de la manera propuesta, recalcó el canciller uruguayo, se profundizarían los términos de la integración regional, lo cual obviamente es el camino a seguir El país debe sumarse a este tipo de procesos y debe encontrarse la manera de influir positivamente en ellos. 